or remission. Rescue rates were $7.3 \%$ for bari $4 \mathrm{mg}, 17.1 \%$ for bari $2 \mathrm{mg}$. Most rescued patients could regain LDA or remission. Dose reduction was associated with a lower rate of non-serious infections; rates of SAEs and AEs leading to discontinuation were similar across groups.

Conclusions: These data indicate that $4 \mathrm{mg}$ once daily was the most efficacious dose of bari for pts with RA; increases in disease activity were consistently seen with dose reduction from $4 \mathrm{mg}$ to $2 \mathrm{mg}$ in well-controlled pts. However, after step-down most pts could maintain LDA or remission, or recapture control with return to $4 \mathrm{mg}$ if needed. Attempted dose taper may be a reasonable consideration for some pts following induction of sustained disease control with bari $4 \mathrm{mg}$.

Disclosure of Interest: T. Takeuchi Consultant for: Pfizer Japan, Astra Zeneca KK, Eli Lilly Japan KK, Novartis Pharma KK, Daiichi Sankyo Ltd, Nipponkayaku Ltd, Janssen Pharma KK, Merck Serono Ltd, Takeda Pharma Ltd, Mitsubishi Tanabe Pharma, Astellas Pharma, Abbvie GK, Bristol-Myers KK, Asahi Kasei Medical KK, Speakers bureau: Celtrion, Nipponkayaku Ltd, Pfizer Japan, UCB Japan, Daiichi Sankyo Ltd, Takeda Pharma Ltd, Chugai Pharma Ltd, Abbvie GK, Bristol-Myers KK, Eisai Co Ltd, Mitsubishi Tanabe Pharma, Janssen Pharma KK, Astellas Pharma, M. Genovese Grant/research support from: Eli Lilly and Company, Abbvie, Astellas, Galapagos, Pfizer, Vertex, Consultant for: Eli Lilly and Company, Abbvie, Astellas, Galapagos, Pfizer, Vertex, B. Haraoui Grant/research support from: Amgen, BMS, UCB, Consultant for: Abbvie, Amgen, BMS, Celgene, Janssen, Eli Lilly and Company, Pfizer, Roche, UCB, Speakers bureau: Pfizer, UCB, L. Xie Employee of: Eli Lilly and Company, R. Klar Employee of: Quintiles IMS Holdings, Inc., A. Luisa Pinto Correia Employee of: Eli Lilly and Company, T. Rooney Shareholder of: Eli Lilly and Company, Employee of: Eli Lilly and Company, S. Otawa Employee of: Eli Lilly and Company, J. Smolen Grant/research support from: from Abbvie, Janssen, Eli Lilly and Company, MSD, Pfizer, Roche, Consultant for: Abbvie, Amgen, Astra-Zeneca, Astro, BMS, Celgene, Celltrion, Chugai, Gilead, Glaxo, ILTOO, Janssen, Eli Lilly and Company, Medimmune, MSD, Novartis-Sandoz, Pfizer, Roche, Samsung, Sanofi, UCB, Speakers bureau: Abbvie, Amgen, Astra-Zeneca, Astro, BMS, Celgene, Celltrion, Chugai, Gilead, Glaxo, ILTOO, Janssen, Eli Lilly and Company, Medimmune, MSD, Novartis-Sandoz, Pfizer, Roche, Samsung, Sanofi, UCB DOI: 10.1136/annrheumdis-2017-eular.1073

\section{SAT0073 MIR-186-5P TARGETING IL-33 GENE AS BIOMARKER TO PREDICT SUBCLINICAL ATHEROSCLEROSIS IN PATIENTS WITH EARLY RHEUMATOID ARTHRITIS}

T.H. Cheng ${ }^{1}$, Q. Shang ${ }^{1}$, W.Y. Mak ${ }^{1}$, M. Li ${ }^{1}$, K.Y. Kwok ${ }^{2}$, I.C.W. Yim ${ }^{3}$, E.K.M. Li ${ }^{1}$, P.C.H. Wong ${ }^{4}$, V.W.N. Lao ${ }^{5}$, H.T. Pang ${ }^{5}$, L.S. Tam ${ }^{1} .{ }^{1}$ Department of Medicine and Therapeutics, the Chinese University of Hong Kong; ${ }^{2}$ Department of Medicine, Queen Elizabeth Hospital; ${ }^{3}$ Department of Medicine, Tseung Kwan O Hospital; ${ }^{4}$ Department of Medicine and Therapeutics, Prince of Wales Hospital; ${ }^{5}$ Department of Medicine and Geriatrics, Kwong Wah Hosptial, Hong Kong, Hong Kong

Background: Patients with rheumatoid arthritis (RA) die prematurely compared with the general population, primarily because of cardiovascular diseases (CVD). Interleukin-33 (IL-33) is a member of the IL-1 cytokine family which was important in the pathogenesis of RA and development of CVD. Blood IL-33 protein was not detectable in most subjects, even in RA patients. Thus, the usability of IL-33 as a biomarker for CVD is limited. MicroRNAs (miRNAs) are small non-coding RNAs that function as post-transcriptional regulators of gene expression.

Objectives: This study was to ascertain if dysregulated miRNAs targeting IL-33 gene in early RA (ERA) patients were associated with subclinical atherosclerosis in ERA patients.

Methods: 76 ERA patients were recruited in this cross-sessional study. Potential miRNAs binding to 3 'UTR of the IL-33 gene were predicted by miRanda (www.microRNA.org). 10 miRNAs with highest possibility targeting functional sites of $I L-33$ gene were quantified in cell free plasma samples using a $2^{\Delta C t}$ method. Caenorhabditis elegans miR-39 (cel-miR-39) was used as spike-in control. The results were then log transferd. Carotid plaque (CP) was measured and identified at bilateral common carotid artery, bulb, and proximal internal carotid artery using a high-resolution B mode ultrasound. Receiver-operating characteristic curve (ROC) analysis was performed to determine the discriminating power of the miRNA for the presence of $\mathrm{CP}$

Results: CPs were identified in 26/76 (34\%) subjects (CP+ group). Subjects in the $C P+$ group were older [ $58 \pm 10$ vs $48 \pm 11$ years old, $p=0.001]$, predominantly male [48 $(42.3 \%)$ vs $43(14.0 \%), p=0.006]$, with a higher C-reactive protein (CRP) level [24.9 \pm 25.0 vs $11.8 \pm 13.7 \mathrm{mg} / \mathrm{dL}, p=0.018]$ and higher cardiovascular risk [Framingham risk score (FRS): $12.8 \pm 11.6$ vs $5.7 \pm 6.8, p=0.008$ ] (Table 1). All miRNAs were detected in $>80 \%$ of subjects in both group. Plasma level of miR-186-5p in the CP+ group was significantly higher than that in the CPgroup [log miRNA: $3.28 \pm 3.21$ vs $2.58 \pm 1.13 p=0.008$ ]. It was still significant after adjusting age, sex, plasma CRP and FRS $(p=0.030)$ (Table 1). Using multivariate logistic regression, miRNA-186-5 $p$ was an independent predictor of the presence of carotid plaque (OR: $1.919,95 \% \mathrm{Cl}=1.096-3.361, p=0.023$ ) after adjustment of FRS and CRP level. [Area under the ROC (AUC) $0.66,95 \% \mathrm{Cl}: 0.60-0.80$ $p=0.024]$.

Conclusions: miR-186-5p was an independent predictor for presence of subclinical atherosclerosis and may serve as a novel biomarker for risk stratification in ERA patients with mild to moderate cardiovascular risk.
Table 1 - Characteristics of patients with and without carotid plaque

\begin{tabular}{|c|c|c|c|c|c|c|c|c|}
\hline \multirow[b]{4}{*}{ Age } & \multicolumn{6}{|c|}{ Carotid Plaque } & \multirow{4}{*}{$\begin{array}{c}p \\
0.001\end{array}$} & \multirow{4}{*}{$p^{*}$} \\
\hline & \multirow{2}{*}{\multicolumn{3}{|c|}{$\begin{array}{c}\text { Absence } \\
(n=50)\end{array}$}} & \multirow{2}{*}{\multicolumn{3}{|c|}{$\begin{array}{c}\text { Presence } \\
(n=26)\end{array}$}} & & \\
\hline & & & & & & & & \\
\hline & 48 & \pm & 11 & 58 & \pm & 10 & & \\
\hline Gender, male & 43 & & $14.0 \%$ & 15 & & $42.3 \%$ & 0.006 & \\
\hline $\mathrm{CRP}, \mathrm{mg} / \mathrm{dL}$ & 11.8 & \pm & 13.7 & 24.9 & \pm & 25.0 & 0.018 & \\
\hline Franmingham Risk Score & 5.7 & \pm & 6.8 & 12.8 & \pm & 11.6 & 0.008 & \\
\hline \multicolumn{9}{|l|}{$\log \operatorname{miRNA}$} \\
\hline miR_9_5p & 0.39 & \pm & 0.99 & 0.26 & \pm & 0.36 & 0.809 & 0.225 \\
\hline miR_382_5p & 0.87 & \pm & 0.88 & 0.94 & \pm & 0.82 & 0.809 & 0.730 \\
\hline miR_377_3p & 0.69 & \pm & 0.61 & 0.94 & \pm & 0.83 & 0.227 & 0.550 \\
\hline miR_590_3p & 0.10 & \pm & 0.20 & 0.33 & \pm & 0.61 & 0.684 & 0.222 \\
\hline miR_499a_5p & 0.11 & \pm & 0.17 & 0.19 & \pm & 0.29 & 0.809 & 0.406 \\
\hline miR_145_5p & 2.43 & \pm & 1.05 & 3.30 & \pm & 1.82 & 0.227 & 0.091 \\
\hline miR_542_3p & 0.08 & \pm & 0.27 & 0.08 & \pm & 0.14 & 0.373 & 0.886 \\
\hline miR_186_5p & 2.58 & \pm & 1.13 & 3.28 & \pm & 1.21 & 0.008 & 0.030 \\
\hline miR_214_3p & 0.41 & \pm & 0.66 & 0.61 & \pm & 0.65 & 0.091 & 0.085 \\
\hline miR_496 & 0.14 & \pm & 0.32 & 0.17 & \pm & 0.25 & 0.809 & 0.546 \\
\hline
\end{tabular}

Disclosure of Interest: None declared

DOI: 10.1136/annrheumdis-2017-eular.2840

\section{SAT0074 PERSISTENCE WITH METFORMIN TREATMENT AND ONSET OF RHEUMATOID ARTHRITIS}

M.E. Naffaa ${ }^{1}$, V. Rosenberg ${ }^{2}$, G. Chodick $^{2,3}$, V. Shalev ${ }^{2,3}$, S. Tiosano ${ }^{3,4}$, H. Amital ${ }^{3,4}$. ${ }^{1}$ Rheumatology unit, Galilee Medical Center, Nahariya; ${ }^{2}$ Maccabi Healthcare Services; ${ }^{3}$ Sackler Faculty of Medicine, Tel-Aviv University, Tel-Aviv; ${ }^{4}$ Internal Medicine 'B', Sheba Medical Center, Ramat-Gan, Israel

Background: Several studies have suggested that metformin, an oral hypoglycemic agent, possess an anti-inflammatory property and may have a role in the treatment of rheumatoid arthritis (RA) ${ }^{1,2}$, but little is known on its preventive effects.

Objectives: To examine the association between persistence with metformin and the onset of RA.

Methods: Using the computerized medical database of a large health organization in Israel (Maccabi Healthcare Services, MHS) we have identified incident RA cases among new users of metformin between 1998 and 2014. Included were patients aged 18 or above with one year of follow up before and after the therapy initiation. RA was defined according to physician diagnoses. Participants were followed until the earliest of the following dates: onset of RA, leaving MHS, death, end of follow up (1.1.2016). Persistence with metformin was assessed by calculating the mean proportion of follow-up days covered (PDC) with metformin during the study period.

Results: A total of 113,749 eligible patients were included. During the study follow up period $(794,386$ person-years) we identified 600 incident cases (incidence rate of 75 cases per $100,000 \mathrm{PY}$ ). The incidence of RA in women (111 per 100,000 PY) was higher compared to men (42 per 100,000 PY). In a multivariable model, persistence with metformin (PDC $\geq 80 \%$ ) was associated with lower risk of RA (hazard ratio $(\mathrm{HR}) 0.66$; 95\% confidence interval $(\mathrm{Cl})$ 0.53-0.82) compared to non-persistent participants $(\mathrm{PDC}<20 \%$ ). Figure 1 shows the hazard function according to persistence with metformin treatment. Similar risk reduction was observed among men but did not reach statistical significance $(\mathrm{HR}=0.85 ; 95 \% \mathrm{Cl}$ $0.54-1.32)$

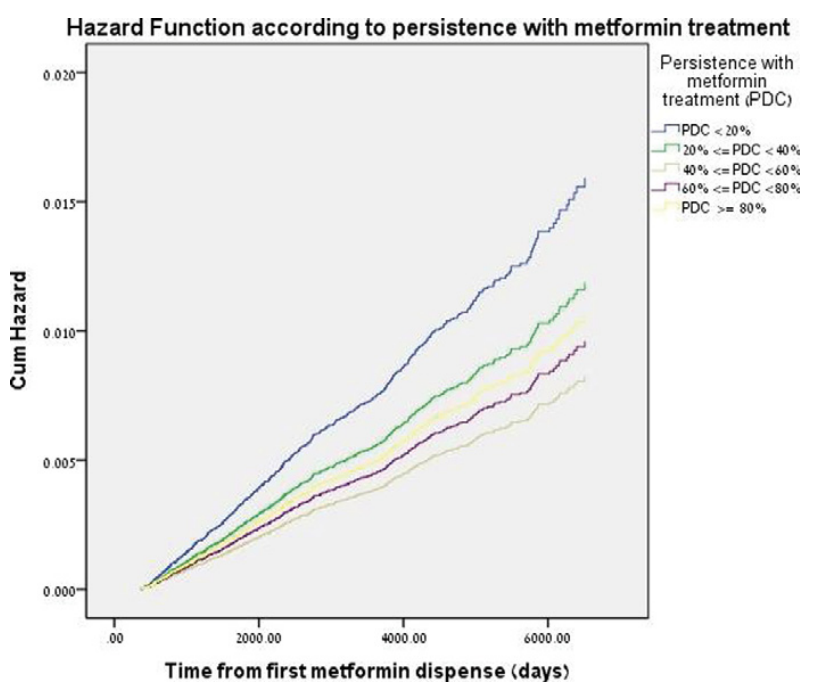

Conclusions: In the present study, we observed an association between high persistence to metformin therapy and reduced risk of developing RA in women. 
Disclosure of Interest: None declared

DOI: 10.1136/annrheumdis-2017-eular.4226

\section{SAT0075 DOES EARLY REMISSION LEAD TO BETTER 5-YEAR OUTCOMES THAN LOW DISEASE ACTIVITY? RESULTS FROM THE REAL LIFE NOR-DMARD STUDY}

V. Norvang, I.C. Olsen, E. Lie, E.K. Kristianslund, T.K. Kvien, E.A. Haavardsholm, T. Uhlig. Department of Rheumatology, Diakonhjemmet Hospital, Oslo, Norway

Background: When initiating therapy with synthetic disease-modifying antirheumatic drugs (sDMARDs) in patients with rheumatoid arthritis (RA), the recommended target is remission or low disease activity (LDA). Limited data exist on the impacts of reaching remission rather than LDA on long-term outcomes. Objectives: To compare RA-patients who achieved Simplified Disease Activity Index (SDAI) remission versus LDA 6 months after initiating SDMARD therapy, with regard to physical function, Health Related Quality of Life (HRQoL) and disease activity during 5 years of follow-up in a routine clinical setting.

Methods: Data were provided NOR-DMARD, a prospective multicentre longitudinal observational study. We selected DMARD-naïve patients with RA enrolled between December 2000 and April 2009 who had a registered visit with available SDAI status 6 months after initiating SDMARD therapy. Data on each patient were collected at baseline, after 3, 6 and 12 months, and yearly thereafter, including the modified Health Assessment Questionnaire (MHAQ), the Medical Outcomes Study 36-item Short-Form Health Survey (SF-36) with Physical and Mental Components Summary scores (PCS and MCS, respectively) and SF-6D, and assessments that allowed the calculation of the composite disease activity scores SDAI, Clinical Disease Activity Index (CDAI) and the Disease Activity Score based on 28 joint counts (DAS28). Multivariate linear mixed models were used to explore the effect of SDAI status at 6 months on physical function (MHAQ), HRQoL (SF-36 PCS and MCS, SF-6D) and disease activity (SDAI, CDAI, DAS28) during 5 year follow-up. The statistical models were adjusted for age, gender, disease duration and baseline disease activity. Furthermore, we performed mixed model analyses separately for patients in LDA, MDA and HDA at baseline, exploring the impact of SDAI status at 6 months on long-term disease activity in each sub-group.

Results: Of 1148 eligible patients, 867 patients (75.5\%) started with methotrexate in monotherapy and $281(24.5 \%)$ started with another sDMARD or sDMARD combination. Patients in SDAI remission $(n=145 ; 16.6 \%)$ rather than LDA $(n=454$; $39.5 \%) 6$ months after initiating therapy had better physical function (MHAQ, estimated mean difference $0.11-0.20, \mathrm{p}<0.02)$, higher SF-36 PCS $(4.13-8.16$, $\mathrm{p}<0.003)$ and SF-6D $(0.06-0.12, \mathrm{p}<0.0001)$, and lower disease activity (SDAI, $2.24-5.15, p<0.05$ ) for all visits during 5 years of follow-up. Stratified mixed models analyses of patients in SDAI LDA, MDA and HDA at baseline, resulted in an overall significant long-term beneficial effect of achieving remission rather than LDA at 6 months; however, the differences were less distinct for patients who were already in a state of LDA at baseline.

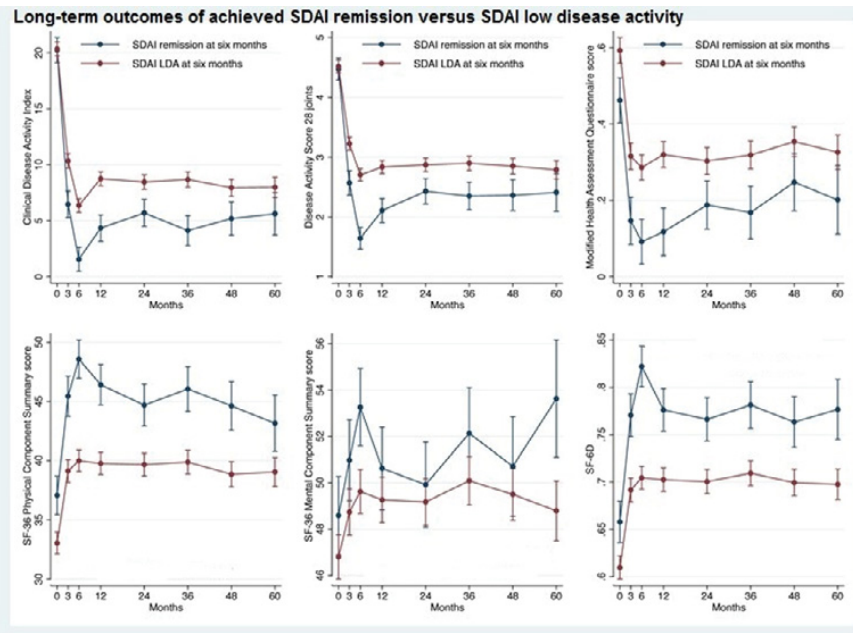

Conclusions: The achievement of SDAI remission 6 months after initiating DMARD-therapy was associated with favourable long-term outcomes compared with the achievement of SDAI low disease activity. The results from the study support that stringent remission is the optimal treatment target in patients with RA.

Disclosure of Interest: V. Norvang: None declared, I. Olsen: None declared, E. Lie Consultant for: AbbVie, Celgene, Hospira, Pfizer, UCB, E. Kristianslund: None declared, T. Kvien Consultant for: AbbVie, Biogen, BMS, Boehringer, Ingelheim, Celltrion, Eli Lilly, Epirus, Janssen, Merck-Serono, MSD, Mundipharma, Novartis, Oktal, Orion Pharma, Hospira/Pfizer, Roche, Sandoz, UCB, E. Haavardsholm Grant/research support from: AbbVie, Pfizer, Roche, MSD, UCB, Consultant for: AbbVie, Pfizer, Roche, Eli Lilly, Celgene, UCB, T. Uhlig: None declared DOI: 10.1136/annrheumdis-2017-eular.3874

\section{SAT0076 SERUM LEVEL OF SYNDECAN-4 AND ITS CORRELATION WITH CLINICAL PARAMETERS IN RHEUMATOID ARTHRITIS PATIENTS}

X. Ye, J. Zhao, Z. Zhang. Rheumatology and Clinical Immunology Department, Peking University First Hospital, Beijing, China

Background: Heparan sulfate proteoglycan syndecan-4 plays an important role in inflammation. However, the role of syndecan-4 in rheumatoid arthritis (RA) has not yet been elucidated.

Objectives: To detect serum level of syndecan-4 in RA patients and investigate its correlation with RA clinical parameters.

Methods: The concentration of serum syndecan-4 was assayed by enzyme-linked immunosorbent assay (ELISA). 43 patients' serum samples from our RA cohort study between 2014 and 2016, and 20 age- and gender-matched osteoarthritis (OA) patients' serum samples were collected and analyzed. Compared the serum syndecan- 4 levels in RA patients with DAS $28 \geq 3.2$ and DAS $28<3.2$ by Wilcoxon signed rank test. The relationships between serum syndecan-4 levels and RA clinical parameters (DAS28, rheumatoid factor (RF), erythrocyte sedimentation rate, C-reactive protein, etc.) were analyzed.

Results: Baseline serum syndecan-4 levels of RA patients were significantly higher than the matched OA patients $(1101.56 \mathrm{pg} / \mathrm{mL}$ vs $281.41 \mathrm{pg} / \mathrm{mL}, \mathrm{p}<0.001)$. In RA patients who had sera both at the point of DAS28 $\geq 3.2$ and DAS $28<3.2$ $(n=13)$, we found that the former syndecan-4 levels were higher than the latter (1666.22 $\mathrm{pg} / \mathrm{mL}$ vs $1378.34 \mathrm{pg} / \mathrm{mL}, \mathrm{p}=0.65$ ). The levels of serum syndecan-4 and RF were significantly and positively correlated in RA patients $(r=0.696, p=0.008)$. Furthermore, there is a tendency that serum syndecan-4 levels were higher in the RF-positive $(n=31)$ than in the RF-negative $(n=12) R A$ patients $(1344.43 \mathrm{pg} / \mathrm{mL}$ vs $971.27 \mathrm{pg} / \mathrm{mL}, \mathrm{p}=0.078$ )
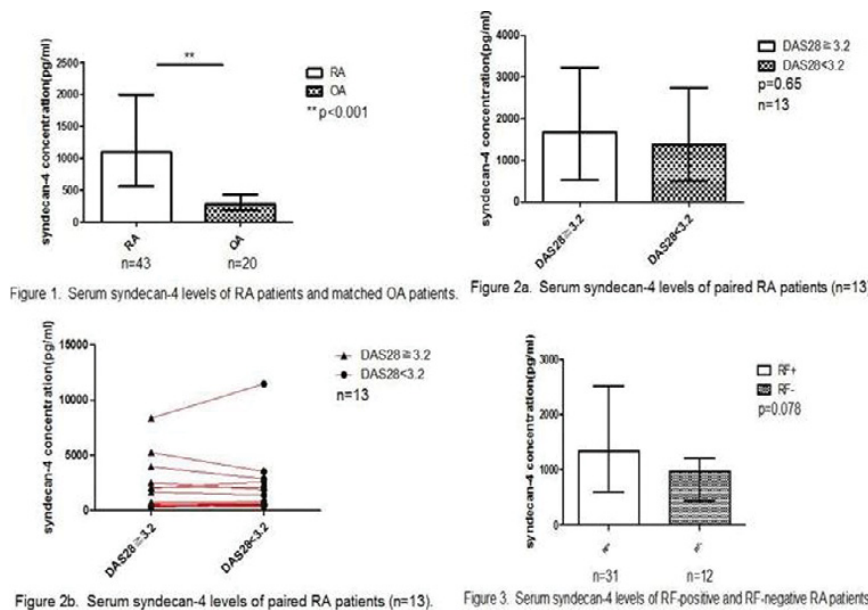

Conclusions: Compared with age- and gender- matched OA patients, serum syndecan-4 concentration is significantly higher in RA patients. Serum syndecan-4 level is positively correlated with RF. Syndecan-4 may play an important role in thes pathogenesis of RA. Further investigation is required to study the mechanism of syndecan-4 in RA.

References:

[1] Zhao J, Guo J, Wang L, et al. The role of a proliferation-inducing ligand (APRIL) in the pathogenesis of rheumatoid arthritis. Scand J Rheumatol 2014;43(6):462-9

[2] Patterson AM, Cartwright A, David G, et al. Differential expression of syndecans and glypicans in chronically inflamed synovium. Ann Rheum Dis 2008 May;67(5):592-601.

[3] Endo T, Ito K, Morimoto J, et al. Syndecan 4 Regulation of the Development of Autoimmune Arthritis in Mice by Modulating B Cell Migration and Germinal Center Formation. Arthritis Rheumatol 2015 Sep;67(9):2512-22.

Acknowledgements: We are indebted to all the patients who kindly participated in this study. This study was partly supported by Peking University Clinical Research Institute.

Disclosure of Interest: None declared

DOI: 10.1136/annrheumdis-2017-eular.1091

\section{SAT0077 CLINICAL FEATURES AND PERFORIN A91V GENE ANALYSIS IN SO-JIA CHILDREN WITH MACROPHAGE ACTIVATION SYNDROME}

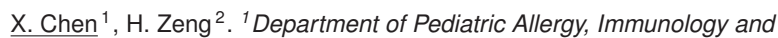
Rheumatolog; ${ }^{2}$ Department of Pediatric Allergy, Immunology and Rheumatology, Guangzhou Women and Children's Medical Center, Guangzhou, China

Objectives: Macrophage activation syndrome (MAS) is a severe, potentially life-threatening syndrome.Here we aim to review the precipitating events,clinical features, treatment, outcome and perforin A91V gene analysis in systemic onset juvenile idiopathic arthritis (SoJIA) children with MAS. 